\title{
APLIKASI BOX MODEL SEDERHANA UNTUK ESTIMASI KONSENTRASI POLUTAN BLACK CARBON DI ATMOSFER
}

\author{
Haryono Setiyo Huboyo"), Budi Prasetyo Samadikun" \\ ${ }^{1}$ )Departemen Teknik Lingkungan, Fakultas Teknik, Universitas Diponegoro, Jl. Prof. Soedarto, \\ $\mathrm{SH}$, Kampus Undip Tembalang, Semarang, Indonesia 50275 \\ e-mail: huboyo@undip.ac.id
}

\begin{abstract}
Abstrak
Box Model adalah salah satu pemodelan kualitas udara yang menggunakan formulasi matematis parameter-parameter yang mempengaruhi konsentrasi polutan di udara yaitu berupa arah dan kecepatan angin, serta ketinggian. Black carbon adalah komponen utama jelaga dan dihasilkan dari pembakaran bahan bakar fosil dan biomassa yang tidak sempurna serta memiliki dampak pemanasan pada iklim 460-1500 kali lebih kuat dari $\mathrm{CO}_{2}$. Tujuan dari penelitian ini adalah untuk mengetahui estimasi konsentrasi polutan black carbon di atmosfer dengan menggunakan pemodelan Box Model. Pengukuran PM 2.5 menggunakan HVAS (High Volume Air Sampler) dengan metode gravimetri kemudian pengujian black carbon pada $P M_{2,5}$ menggunakan metode reflektansi dengan menggunakan EEL Smokestain Reflectometer, kemudian melakukan perhitungan estimasi black carbon dengan box model. Pengambilan sampel dilakukan pada lima titik yang tersebar di kota Semarang sebanyak tiga kali pengukuran. Hasil penelitian didapatkan bahwa rata-rata perhitungan estimasi black carbon menggunakan box model tidak jauh berbeda atau relatif sama dengan rata-rata hasil pengujian black carbon yang didapatkan dari sampel pengukuran di lapangan.
\end{abstract}

Kata kunci: air pollution, black carbon, box model, $P M_{2,5}$

\begin{abstract}
Box Model is one of the air quality modeling that uses mathematical formulation parameters that affect the concentration of pollutants in the air in the form of wind direction and speed, and altitude. Black carbon is a major component of soot and is produced from incomplete burning of fossil fuels and biomass and has a warming effect on climate 460-1500 times stronger than $\mathrm{CO}_{2}$. Black carbon is usually contained in $\mathrm{PM}_{2.5}$ because it comes from anthropogenic emissions. The purpose of this study was to determine the estimated concentration of black carbon pollutants in the atmosphere in the city of Semarang by using Box Model modeling. The $P_{2.5}$ measurements were conducted using HVAS (High Volume Air Sampler) gravimetrically then black carbon on $P_{2.5}$ was analyzed using reflectance method with EEL Smokestain Reflectometer. The sampling was carried out at five points spread in Semarang city three times. The results showed that the average estimation of black carbon using a box model was not much different or relatively as much as the average black carbon test results obtained from measurement samples in the field.
\end{abstract}

Keywords: air pollution, black carbon, box model, $P M_{2,5}$

\section{Pendahuluan}

Karbon hitam (black carbon) adalah komponen utama jelaga dan dihasilkan dari pembakaran bahan bakar fosil dan biomassa yang tidak sempurna. Black carbon memiliki dampak pemanasan pada iklim 460-1500 kali lebih kuat dari $\mathrm{CO}_{2}$ (Bond et al. 2013). Masa hidupnya bervariasi dari beberapa hari sampai beberapa minggu. Saat tersimpan di atas es dan salju, karbon hitam menyebabkan pemanasan atmosfir dan peningkatan laju leleh. Black carbon ini juga mempengaruhi pembentukan awan dan dampak peredaran regional dan pola curah hujan. Karbon hitam selalu dipancarkan dengan partikel-partikel polutan, seperti karbon organik dan sulfat, yang dapat memiliki efek netral atau bahkan pendinginan pada iklim (Hovart, 1997).

Box model digunakan untuk menduga rata-rata konsentrasi polutan di suatu daerah,yang disumsikan sebagai kotak dimana sumber emisi tersebar merata di permukaan bawah kotak. Selanjutnya, polutan dibawa dan didistribusikan dari daerah sumber oleh gerak lateral sesuai dengan arah 
angin. Model ini menganggap suatu wilayah dan kota sebagai suatu kotak. Yang didalam kotak tersebut terjadi sebuah aktivitas yang menghasilkan gas emisi. Model ini memperhitungkan faktor meteorologi berupa arah dan kecepatan angin, serta ketinggian mixing height (boundary layer) (Hassan dan Crowther 1998).

Titik sampling pada penelitian ini terdapat lima titik yaitu Tugu, Pleburan di Semarang Selatan, Pedurungan, Ngesrep di Banyumanik, dan Gunung Pati. Pengujian black carbon dilakukan di laboratorium PSTNT Batan Bandung. Cahaya yang direfleksikan atau diserap pada filter sampel bergantung pada konsentrasi partikel, densitas, refraksi indeks dan ukuran (Hovart, 1997).

Tujuan dari penelitian ini adalah untuk mengetahui estimasi konsentrasi polutan black carbon di atmosfer dengan menggunakan pemodelan Box Model. Dengan adanya penelitian ini diharapkan dapat menjadi salah satu informasi bahwa pengurangan emisi black carbon penting untuk dilakukan.

\section{Metodologi Penelitian}

Kegiatan penelitian terbagi menjadi tiga kegiatan, yaitu yang pertama kegiatan inventarisasi emisi black carbon, pengujian dan analisis di laboratorium, dan kegiatan perhitungan dan analisis menggunakan model. Berikut ini adalah kegiatan metodologi yang dilakukan:

\section{a. Inventarisasi Emisi Black Carbon}

Sumber emisi sektor domestik diasumsikan berupa konsumsi LPG dari setiap rumah tangga berdasarkan tingkat kesejahteraannya. Untuk mendapatkan data konsumsi LPG dilakukan survey kepada 3 contoh kelurahan. Setelah mendapatkan data tersebut, maka dapat ditentukan konsumsi LPG tiap kecamatan dengan menggunakan data jumlah penduduk berdasarkan tingkat kesejahteraan yang terdapat dalam Badan Pusat Statistik kota Semarang. Berikut ini adalah data konsumsi LPG pada kelima kecamatan lokasi pengambilan sampel di kota Semarang:

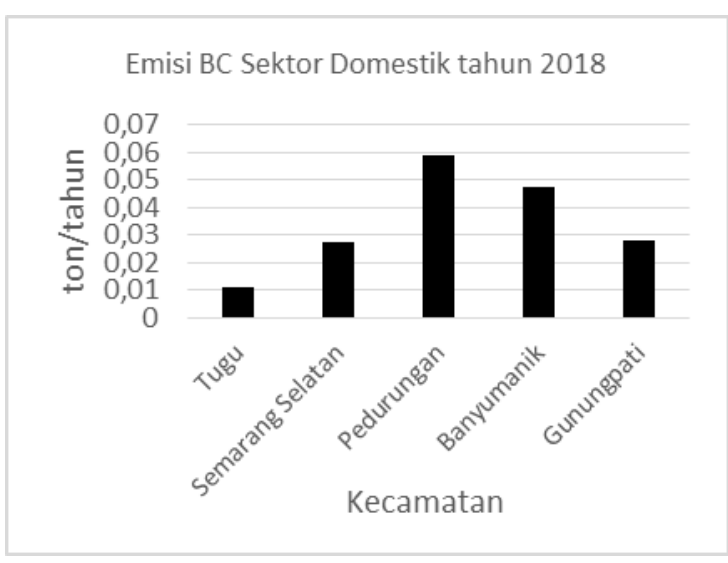

Gambar 1. Emisi BC Sektor Domestik Kota Semarang Tahun 2018

Untuk menghitung beban emisi black carbon dilakukan pendekatam rumus berikut:

$\mathrm{BE}=\mathrm{KK} \times \mathrm{FE}$

Dimana:

$\mathrm{KK}$ = jumlah KK berdasarkan kelas di kecamatan $\mathrm{FE}=$ faktor emisi BC sektor domestik

Sumber emisi sektor industri didapat dari data industri yang ada di kecamatan sebagai berikut:

Tabel 1. Daftar Industri yang Terdapat di Kecamatan

\begin{tabular}{llccc}
\hline No & Kecamatan & $\begin{array}{l}\text { Industri } \\
\text { Besar }\end{array}$ & $\begin{array}{l}\text { Industri } \\
\text { Kecil }\end{array}$ & $\begin{array}{c}\text { Jumlah } \\
\text { Industri }\end{array}$ \\
\hline 1 & Tugu & 18 & 12 & 30 \\
2 & $\begin{array}{l}\text { Semarang } \\
\text { Selatan }\end{array}$ & 2 & 3 & 5 \\
3 & Pedurungan & 11 & 15 & 26 \\
4 & Banyumanik & 4 & 9 & 13 \\
5 & $\begin{array}{l}\text { Gunung } \\
\text { Pati }\end{array}$ & 1 & 4 & 5 \\
\end{tabular}

Pendekatan formula untuk menghitung beban emisi black carbon sebagai berikut:

$B C=$ konsentrasi $\mathrm{PM} \times 10 \%$

Sedangkan untuk sumber emisi black carbon sektor transportasi on road digunakan dengan memakai VKT (Vehicle Kilometer Traveled) tiap jenis kendaraan bermotor. Berikut ini ditunjukkan tabel total VKT tiap jenis kendaraan bermotor. 
Tabel 2. VKT Sumber Total Kendaraan

\begin{tabular}{|c|c|}
\hline $\begin{array}{l}\text { Jenis Kendaraan } \\
\text { Bermotor }\end{array}$ & $\begin{array}{c}\text { VKT Sumber Total } \\
(\mathrm{km} / \mathrm{tahun})\end{array}$ \\
\hline Bus & 142.075 .885 \\
\hline Truk & 793.501 .520 \\
\hline $\begin{array}{l}\text { Mobil Penumpang } \\
\text { Bensin }\end{array}$ & 3.361 .728 .117 \\
\hline $\begin{array}{l}\text { Mobil Penumpang } \\
\text { Diesel }\end{array}$ & 103.970 .973 \\
\hline Motor & 18.121 .476 .200 \\
\hline
\end{tabular}

Dan untuk menghitung beban emisi BC dari sektor transportasi on road digunakan persamaan:

$\mathrm{BE}=\mathrm{VKT} \times \mathrm{FE}$

Dimana:

VKT = Vehicle Kilometer Traveled

FE = Faktor emisi BC kendaraan

b. Kegiatan Pengujian dan Analisis Laboratorium

Kegiatan sampling di lapangan untuk mengambil $\mathrm{PM}_{2,5}$ digunakan rumus:

$\mathrm{Mp}=\mathrm{M} 2-\mathrm{M} 1$

Dimana:

$\mathrm{Mp}=$ berat partikulat $\mathrm{PM} 2,5$

M2 = berat filter setelah sampling

M1 = berat filter sebelum sampling

Setelah pengujian black carbon di laboratorium maka dilakukan perhitungan black carbon berdasarkan perhitungan rumus:

$$
\mathrm{BC}=\frac{\left[\left[1000 \times \log \left(\frac{(10)}{\mathrm{T}}\right)+2,29\right]\right.}{2 !}+\frac{\mathrm{A}}{\mathrm{V}}
$$

Dimana :

$\mathrm{I}=$ reflektans filter kosong

$\mathrm{I}$ = reflektans sampel yang diukur

$A=$ luas sampel yang diukur

$\mathrm{V}=$ volume udara sampel yang diukur

c. Kegiatan Perhitungan dan Analisis Model

Untuk melakukan perhitungan estimasi black carbon digunakan rumus:

$$
C=b+(q \cdot p) /(u \cdot H)
$$

Dimana :

$\mathrm{b}=$ hasil konsentrasi $\mathrm{BC}$ di lapangan

$\mathrm{q}=$ beban emisi $\mathrm{BC}$ hasil inventarisasi

$\mathrm{p}=$ panjang area lokasi (kecamatan)

$\mathrm{u}=$ kecepatan angin

$\mathrm{H}=$ ketinggian atmosfer

\section{Hasil dan Pembahasan}

Estimasi black carbon yang dilepaskan di udara ambien dihitung pada setiap kecamatan dilakukannya pengukuran.

\section{Perkiraan BC pada Ketinggian h1 dan h2 selama 24 jam}

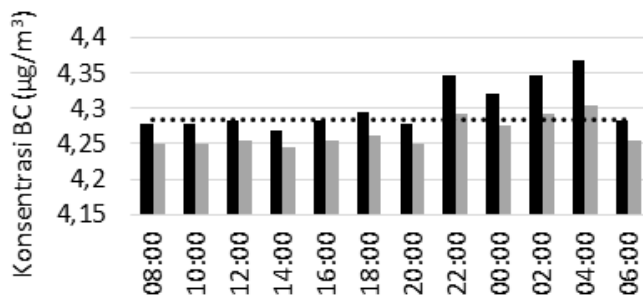

h1 h2 $\quad$ h....... rata-rata

Gambar 2. Estimasi Konsentrasi Black Carbon pada Udara Ambien Kecamatan Tugu

Estimasi konsentrasi black carbon di kecamatan Tugu menunjukkan konsentrasi rata-rata $4,284 \mu \mathrm{g} / \mathrm{m}^{3}$ dan konsentrasi $B C$ pada ketinggian $120 \mathrm{~m}$ lebih tinggi dibanding ketinggian $200 \mathrm{~m}$.

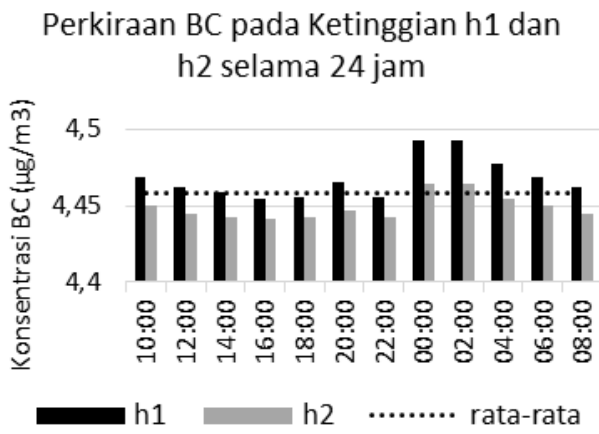

Gambar 3. Estimasi Konsentrasi Black Carbon pada Udara Ambien Kecamatan Kecamatan Selatan

Estimasi konsentrasi black carbon di kecamatan Semarang Selatan rata-rata adalah $4,459 \mu \mathrm{g} / \mathrm{m}^{3}$.

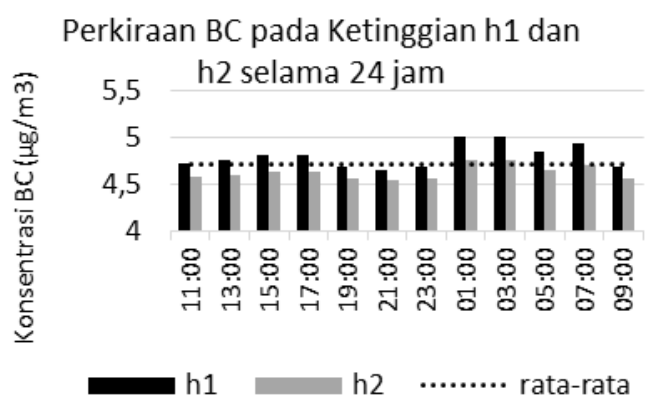

Gambar 4. Estimasi Konsentrasi Black Carbon pada Udara Ambien Kecamatan Pedurungan 
Estimasi black carbon di kecamatan Pedurungan rata-rata sebesar $4,714 \mu \mathrm{g} / \mathrm{m}^{3}$.

\section{Perkiraan BC pada Ketinggian h1 dan h2 selama 24 jam}

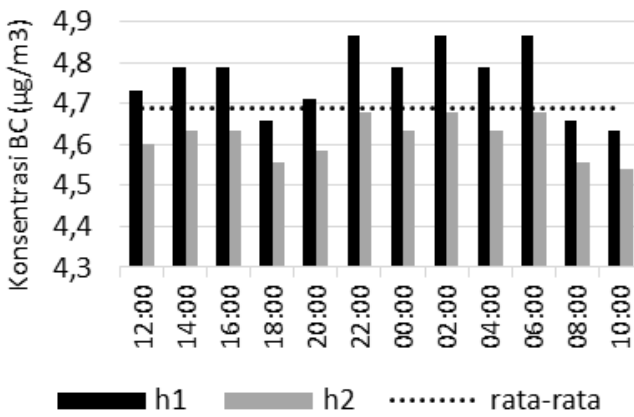

Gambar 5. Estimasi Konsentrasi Black Carbon pada Udara Ambien Kecamatan Banyumanik

Estimasi black carbon di kecamatan Pedurungan rata-rata sebesar $4,689 \mu \mathrm{g} / \mathrm{m}^{3}$

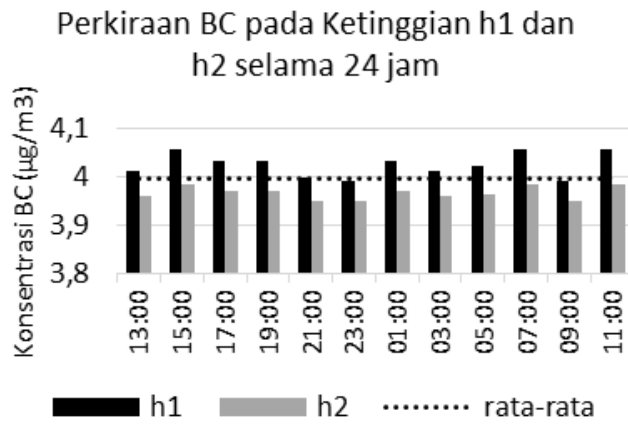

Gambar 6. Estimasi Konsentrasi Black Carbon pada Udara Ambien Kecamatan Gunung Pati

Estimasi black carbon di kecamatan Pedurungan rata-rata sebesar $3,996 \mu \mathrm{g} / \mathrm{m}^{3}$

Secara keseluruhan, hasil perhitungan estimasi konsentrasi black carbon menunjukkan bahwa pada ketinggian 120 meter, konsentrasi black carbon lebih tinggi dibandingkan pada ketinggian 200 meter. Artinya, semakin naik keatas atmosfer, konsentrasi black carbon semakin rendah.
Hal ini dikarenakan bahwa pada prinsip box model, keadaan adalah selalu tetap (steady state). Laju emisi polutannya konstan (relatif tetap). Udara yang bergerak dibatasi dari atas oleh lapisan udara yang stabil pada ketinggian (h). Udara yang bergerak juga dibatasi pada arah tegak lurus terhadap kecepatan angin.

\section{Kesimpulan}

Hasil perhitungan menunjukkan bahwa konsentrasi black carbon pada saat pengukuran relatif hampir sama dengan hasil perhitungan estimasi menggunakan box model yaitu sekitar 6-13\%. Secara keseluruhan, hasil perhitungan estimasi konsentrasi black carbon menunjukkan bahwa pada ketinggian 120 meter, konsentrasi black carbon lebih tinggi dibandingkan pada ketinggian 200 meter.

Ucapan Terima Kasih: Ucapan terima kasih disampaikan kepada Irna Sari Panjaitan yang sudah membantu dalam pelaksanaan penelitian ini.

\section{Daftar Pustaka}

Bond TC, et al. (2013) Bounding the role of black carbon in the climate system: $A$ scientific assessment. J Geophys Res Atmos 118(11):5380-5552, 10.1002/jgrd.50171

BPS, Semarang Dalam Angka (2015). Jumlah KK Berdasarkan Tingkat Kesejahteraannya di Tiap Kecamatan..

Hassan, A.A.,Crowther J.M. 1998. A Simple Model Polutant Concentrations In A Street Canyon. $J$ of Enviromental Monitoring and Assessment 52:269 280.

Hovart, H., Experinmental calibraion for aerosol light absorption measurement using the integrating plate methodSummary of data, Aerosol Science, 28 (1997)1149-1161 